\title{
Muscle Release in the Management of Spasticity in Spinal Cord Injury
}

\author{
I. Eltorai, $\mathbf{M D},{ }^{1} \mathbf{R}$. Montroy, $\mathbf{M D}^{2}$ \\ ${ }^{1}$ Veterans Administration Medical Center, Long Beach, California, USA, ${ }^{2}$ College of \\ Medicine, University of California, Irvine, California, USA.
}

\begin{abstract}
Summary
Muscle spasticity and contractures in the spinal cord injured are a big problem interfering with rehabilitation, leading to inconveniences and complications in these patients. Management is based on pharmacotherapy, physiotherapy and surgeries. The authors are against central neurosurgery except on rare occasions. They have been practicing peripheral surgeries chiefly on muscles and tendons with satisfactory results in selected cases. The guidelines and procedures are presented.
\end{abstract}

Key words: Spasticity; Contractures; Myotenotomy (muscle release); Spinal cord injury.

Spasticity and contractures of the muscular system below the level of spinal cord injury (SCI) are one of the most incapacitating complications of the cord injury (Yarkony et al., 1985). They stand as a formidable obstacle to the rehabilitation of SCI victims, cause a lot of pain, inconvenience ending by contractures and other complications, viz. joint ankylosis, dislocation and subluxation, oedema of the extremities, pressure ulcers, vascular compromise both arterial and venous, falls with subsequent fracture, even pathological fractures, difficulty in positioning and seating of the patients. For these reasons spasticity and contractures should be treated and above all be prevented. Pharmacotherapy (Woolsey, 1981; Pedersen; Duncan et al., 1976; Shears and Nance, 1985) and physical therapy (Guttmann, 1953) should always be given the chance before surgery is considered, particularly in incomplete cases in which spasticity may be of value in supporting the patient especially when there is paraplegia in extension. Neurosurgical interventions, e.g. rhizotomy (Foerster, 1908, 1911; Freeman and Heimburger, 1947, 1948; Gonsette and Andre-Balisaux, 1963; Kerr, 1966; Laitinen et al., 1983; Munro, 1945, 1948; Sindou et al., 1987; Lehmann, 1936), cordotomy (Hyndman, 1943), cordectomy (McLaughlin et al., 1986), myelotomy (Bischof, 1951; Fogel et al., 1985; Weber, 1955), neurotomy, griseotomy (Padovani et al., 1982) and epidural stimulation (Bajd et al., 1985; Campos et al., 1987; Dimitrijevic et al., 1986; Richardson and McLone; Maiman et al., 1987; Romana et al., 1985), etc. (Pourpre, 1960; Schurmann, 1953) are major surgeries and carry morbidity. Besides, their results 
are not permanent. Epidural spinal cord stimulation has lately been advocated but long term results are not well documented. Chemical block of the reflex arc by intrathecal alcohol, phenol with or without the use of contrast medium (Comarr, 1960; Dogliotti, 1933; Gringras, 1948; Kelly and Gautier-Smith, 1959; Lacombe et al., 1966; Liversedge and Maher, 1960; Maher, 1955; Nathan, 1959, 1965; Scott et al., 1985; Sheldon and Bors, 1948), peripheral nerve block (Khalili and Betts, 1967; Khalili et al., 1964) and motor point block (Muller et al., 1987; Halpern and Meelhuysen, 1966) have been practiced. Intrathecal baclofen (Muller et al., 1987; Penn and Kroin, 1985) has recently been tried. It has therefore been our policy in the Long Beach Veterans Administration Spinal Cord Center, to practice peripheral surgeries whereby spasticity can be controlled without resorting to major neurosurgeries (Comarr, 1960). Before tendon surgery is planned it is important to apply the following criteria:

1. All triggering factors should be treated, viz. pressure sores, osteomyelitis, high urine residual, genitourinary infections, stones, epididymitis, phimosis, etc., gastrointestinal problems, e.g. ulcers, gall stones, distension, faecal impaction, haemorrhoids, perianal infections and fissures, etc. Other causes should be looked for, e.g. ingrowing toenails, paronychia, hidden fractures, fever, anaemia, malnutrition, drug addiction, heavy smoking, etc. Psychological stresses should be considered (Hohmann, 1954) (Table I).

2. Have all conservative measures been exhausted and failed either partially or totally? That means the use of pharmacotherapy and all physical therapy modalities.

3. Before surgery is considered a thorough neurological evaluation is essential, especially for any preserved motor power, any chances of motor recovery and the effect of surgery on the antagonistic muscles. In older patients a syrinx can be manifested by increasing spasticity usually with increasing pain and if suspicious it should be ruled out by appropriate investigations.

4. The status of the joints for contracture of the capsules, displacement and periarticular ossification should be studied.

5. Careful planning as to which muscle or group of muscles is to be tackled by surgery and what procedure will be performed. One has to ascertain which muscle or muscle group is predominant in the heightened reflex activity. All these criteria are needed to choose the right type of surgery at the right time, neither too early nor too late.

In our series the most common indications for tendon surgery are as follows.

\section{Lower extremity}

1. Hip flexion, hip adduction.

2. Knee flexion contracture, knee extension contracture.

3. Ankle: equinovarus deformity.

4. Toes: flexion contracture, occasionally hallux extension. 
Table I Triggering factors to rule out

\begin{tabular}{ll}
\hline Skin & Pressure sores \\
& Skin infections \\
Wounds \\
Ingrowing toenails \\
Muscles & Paronychia \\
& Active heterotopic ossification \\
& Abscess: i.m. injection \\
Bones & Osteomyelitis \\
& Fractures \\
Joints & Arthritis \\
& UTI \\
& Stones \\
& Perirenal infection \\
& Balanitis \\
& Epididymitis \\
& Dyssynergia \\
& Gastritis \\
& Peptic ulcer \\
GI & Gas distension \\
& Faecal impaction \\
& Megacolon \\
& Haemorrhoids \\
& Anal fissure \\
& Perianal infections \\
& Gall stones \\
& Pancreatitis \\
& Anaemia \\
& Malnutrition \\
& Heavy smoking \\
& Caffeinism \\
& Drug addiction \\
& Psychological stress \\
\hline
\end{tabular}

\section{The hip}

For hip flexion contractures, release of the iliopsoas is the most important procedure. This can be approached in the following ways:

1. Iliopsoas myotomy by the retroperitoneal approach (Michaelis' technique) (Michaelis, 1964).

2. Iliopsoas tenotomy through a thigh approach (Bleck and Holstein, 1963; Keats, 1967). Other flexors may be divided: Rectus femoris, Sartorius.

For hip adductor spasm, obturator neurectomy, preferably by the suprapubic extraperitoneal approach (Michaelis, 1964; Keats, 1967) or by the inguinal approach when combined with adductor tenotomies. Through this latter approach a combined iliopsoas and adductor tenotomy can be performed.

\section{The knee}

For the flexed knee, the flexion deformity of the knee may simply be due to a hamstring contracture or may be secondary to flexion deformity of the hip, 
occasionally to a spastic equinus deformity of the ankle or to overactivity of the spastic gastrocnemius and also prolonged sitting with the knees flexed. Careful evaluation is therefore necessary before the operation is planned and this should be directed towards the primary cause of knee contracture. In many cases, correction of the hip deformity (flexion and/or adduction) automatically corrects the knee deformity. Also Achilles tenotomy or lengthening or gastrocnemius lengthening may correct the knee deformity. That is why in some cases of hamstring tenotomies, the results to the knee are not satisfactory. The muscles to be divided are the gracilis, semitendinosus, semimembranosus and biceps femoris. Comarr has recommended on occasions additional neurectomy of the tibial and peroneal nerves. Tendon lengthening may be considered on these muscles if any functional element is preserved, also tendon transfer.

\section{The ankles}

The most common deformity of the ankle is that of equinus, and this may be combined with a varus or valgus deformity. The triceps surae (gastrocnemius and soleus) act on the knee, ankle and subtaloid joint thus when contracted will be accompanied by knee flexion, varus or valgus deformity. Misplacement of the os calcis and talus results in chronic cases which account for tendon surgery failures. That is why surgery should not be too long delayed. The procedures that are usually adopted are: Achilles tenotomy, Achilles tendon lengthening by Z-plasty or by gastrocnemius release at the junction of the muscle belly with the tendon (tongue-in-groove procedure of Baker) especially when some function is expected. Others combine gastrocnemius denervation (Stoffle's) with the tenotomy or tendon lengthening.

In many cases we have noticed that the release of tension of the triceps surae corrected ankle deformity, reduced the spasticity in the whole leg and even in the contralateral limb. For ambulating patients tendon lengthening is the procedure of choice since tenotomy alone weakens the stability of the ankle. For persistent varus deformity after Achilles tendon lengthening open tenotomy of the tibialis posterior may be attempted. In unilateral severely spastic equinovarus deformity a transfer of the tendon of the tibialis anterior into the sheath of the extensor digitorum communis after section of the latter and removal of a wedge of bone on the lateral side of the foot will correct that deformity. In bilateral cases correction can be achieved by tibialis anterior transfer to the tendon of extensor digitorum comminus without bone wedge removal. For pes equinovalgus the peroneii are transferred to the sheath of the extensor digitorum comminus. For talipes calcaneus it is recommended to do shortening of the Achilles either alone or with a transfer of the flexor hallucis longus or digitorum longus to the tendocalcaneus and occasionally to the os calcis separately.

For severe inversion, if Achilles lengthening does not correct it, then the tendon of the tibialis posterior is rerouted anteriorly to the medial malleolus.

For valgus deformity with pes equinus, the tendo Achilles is lengthened and the peroneii are translocated anterior to the lateral malleolus thus acting as dorsiflexors.

For the varus deformity, the tendon of the tibialis posterior is divided, it may 
be transferred subcutaneously anterior to the ankle and fixed to the cuboid or lateral cuneiform bone.

\section{The toes}

For spastic toes, tenotomies of the flexors or extensors with or without capsulotomies, sometimes basal phalangectomy or amputations have to be done.

\section{Upper extremity}

For the upper extremities the most common contracture deformity is that of elbow flexor. Repeated splintage may be of help but we resorted to biceps brachii tenotomy or lengthening or brachialis myotomy.

The aim of surgery on the muscles and tendons is to allow a spastic muscle to retract and find a new length at rest resulting in correction of the contracture and reduction of the afferent inflow from the muscle to the isolated spinal cord. Tendon lengthening and/or transfer are of great value in patients who have some function preserved such as walking or standing or in whom it is believed to be possible. Tenotomies and myotomies do not necessarily lead to loss of function of the muscle involved. Osseous contact may be re-established by a scar and the muscle may be able to contract, if functioning, again. It is a common observation in our patients to find reunion of the cut Achilles tendon by a bridge of scar necessitating repeated surgery. Our experience consists of surgeries on the tendons mostly by tenotomies in 120 patients comprising 307 procedures as seen in Table II.

Table II Procedures carried out

\begin{tabular}{lr}
\hline Achilles tenotomy & 114 \\
Achilles tendon, lengthen & 3 \\
Adductor tenotomy and myotomy & 34 \\
Obturator neurectomy/neurotomy & 13 \\
Elbow tenotomy and fasciotomy & 12 \\
Hip flexor tenotomy and fasciotomy & 41 \\
Flexor hallucis longus tenotomy & 1 \\
Extensor hallucis longus tenotomy & 2 \\
Flexor tenotomy, knee & 48 \\
Tenotomy toes & \\
$\quad$ Extensor-6, flexor-21 & 27 \\
Finger tenotomies & 2 \\
$\quad$ Flexor-1, extensor thumb-1 & \\
Foot, flexor tenotomy and plantar & 4 \\
fasciotomy, tibialis posterior tenotomy & 2 \\
Femoral neurotomy & 3 \\
Patellectomy with quadriceps tenotomy & 307 \\
Total surgeries &
\end{tabular}

In the last 14 years there were approximately 120 patients who required tendon surgery for spasticity in a total population of approximately 3000, accounting for approximately $4 \%$. The ages ranged between 21 and 74 with an average of 43 years. Duration of spinal cord injury ranged from 1 to 45 years, average 22 years. 
Level of injury was from C3 to L1, most common C5-C6. Anaesthesia was mostly i.v. sedation except in restless patients with jerky extremities and incomplete lesions when the patients were put under general anaesthesia or spinal, particularly for iliopsoas tenotomies. There was no morbidity nor any mortality. Wound sepsis was rarely encountered since we used closed suction drainage for more major myotomies, viz. the iliopsoas and adductor group. The results of the iliopsoas myotomies were encouraging except in patients who had joint problems; capsular contraction, subluxation and dislocation. The latter we now exclude from myotomies. In the flexed knees the results were satisfactory. Those with capsular contracture of the knee had capsulotomy and/or ligamentous section. Subluxation of the knee was an obstacle to correction of the deformity. Skin shortening was similarly an obstacle and in some cases Z-plasty with or without skin grafting was done but we did not force the extension due to possible popliteal vascular compromise. Skin expansion by an expander may be tried. In the ankle tendon lengthening and tenotomies resulted in correction of the equinus deformity and to some extent the varus deformity. However, with Achilles tenotomies if physical therapy does not start as early as possible, recurrences do occur and in some cases re-operation was indicated. Other deformities of the foot were handled by tenotomies and tendon transplants as indicated above. For ankle or foot deformities we did not attempt bone surgeries because of the risk of infection in this patient population.

\section{Conclusions}

Spasticity in spinal man, especially in those with complete lesions can be most incapacitating and should be treated. A choice of one or more lines of treatment depends on the lesion and its manifestations. Conservative treatment should always be tried first, viz. pharmacological and physical therapy after eliminating all source of lowering the threshold of spinal reflex activity. Destructive procedures, e.g. rhizotomy and myelotomy as well as spinal alcohol or phenol block, should be kept as a last resort. Peripheral surgeries, viz. neurotomies, neurectomies, tendon lengthening and transfers, tenotomies and capsulotomies should be tried before embarking on major surgery. Our results on such patients have been satisfactory, based on over 300 procedures performed in the Long Beach Veterans Administration Spinal Cord Injury Center.

\section{References}

Bajd T, Gregoris M, Vodovnik L, Benko H 1985 Electrical stimulation in treating spasticity resulting from spinal cord injury. Archives of Physical Medicine and Rehabilitation 66:515-517.

BischOF W 1951 Die longitudinale myelotomie. Zentralblatt Neurochirurgie 11:79-88.

Bleck EE, Holstein A 1963 Iliopsoas tenotomy for spastic paralytic deformities of the hip. Paper delivered at the annual meeting of the American Academy of Orthopedic Surgeons, Chicago.

Campos RJ, Dimitrijevic MR, Sharkey PC, Sherwood AM 1987 Epidural spinal cord stimulation in spastic spinal cord injury patients. Applied Neurophysiology 50:453-454.

COMARR EA 1960 The use of subarachnoid alcohol injection among spinal cord injury patients. Fournal of the Indian Medical Profession 7:3133-3135, 3141.

COMARR EA 1960 Peripheral operations for relief of spasticity and/or contracture in patients with spinal cord injuries. Clinical Spinal Cord Injury Conference, Veterans Administration Medical Center, Long Beach, CA, October 18-20.

Dimitrijevic MM, Dimitrijevic MR, ILlis LS et al. 1986 Spinal cord stimulation for the control of 
spasticity in patients with chronic spinal cord injury. I. Clinical observations. Central Nervous Sysem Trauma 3:129-144.

Dimitrijevic MR, Illis LS, Nakajima K, Sharkey PC, Sherwood AM 1986 Spinal cord stimulation for the control of spasticity in patients with chronic spinal cord injury. II. Neurophysiologic observations. Central Nervous System Trauma 3:145-152.

Dogliotti AM 1931 Proposta di un nuovo metodo di cura delle algie periferiche. L'alcoolizzazione sottomeningea delle radici posterioro. Considerazioni sulle prime 30 osservazione cliniche. Minerva Medica 1:536-540.

Duncan G, Shahani G, Young R 1976 An evaluation of Baclofen treatment for certain symptoms in patients with spinal cord lesions. Neurology 26:441-446.

Fogel JP, WATERS RL, MAHOMAR F 1985 Dorsal myelotomy for relief of spasticity in spinal injury patients. Clinical Orthopaedics and Related Research 192:137-141.

FOERSTER O 1911 Due behandlung spasticher lahmungen durch resektion hinterer ruckenmarkswurzein. Ergebrisse Chirurgie Orthopadie 2:174-209.

FOERSTER O 1908 Uber eine neue operative methode der behandlung spastischer lahmungen mittels resektion hinterer ruckenmarkswurzein. A Orthop Chir 22:203-223.

FrEeman LW, HeImBURGER RF 1947 The surgical relief of spasticity in paraplegic patients. I. Anterior rhizotomy. Fournal of Neurosurgery 4:435-443.

FREEMAN LW, HEIMBURGER RF 1948 The surgical relief of spasticity in paraplegic patients. II. Peripheral nerve section, posterior rhizotomy, and other procedures. Fournal of Neurosurgery 5:556-561.

GRINGRAS G 1948 Preliminary report on intrathecal alcohol injections in cases of paraplegia. Treat Serv Bull Dept of Vet Aff Canada 3:56-68.

Gonsette R, ANDRE-Balisaux G 1963 Contribution au traitement neurochirurgical de las spasticite des membres inferieurs dans la sclerrose en plaques. Acta Neurologica Belgica 63:460-477.

Guttmann L Clinical Management of Spasticity. Clinical Aspects of Spinal Cord Injury. pp 515529.

GUTTMANN L 1953 The treatment and rehabilitation of patients with injuries of the spinal cord. In: COPE Z (ed) History of the Second World War. HMSO, London, pp 422-516.

HALPERN D, MEELhUYSEN FE 1966 Phenol motor point block in the management of muscular hypertonia. Archives of Physical Medicine and Rehabilitation 47:659-644.

Hohmann GW 1954 Stress and spasticity in paraplegia. Clinical Paraplegia Conference, October 12 14, pp 51-56.

Hyndman OR 1943 Physiology of the spinal cord. II. The influence of cordotomy on existing motor disturbances. Fournal of Nervous and Mental Disease 98:343-358.

KEATS S 1957 Combined adductor-gracilis tenotomy and selective obturator-nerve resection for the correction of adduction deformity of the hip in children with cerebral palsy. Fournal of Bone and Foint Surgery 39-A:1087-1090.

KEATS S 1967 A simple anteromedial approach to the lesser trochanter of the femur for the release of the iliopsoas tendon. Fournal of Bone and Foint Surgery 49-A:612-636.

KELLY R, GAUTIER-SMITH PC 1959 Intrathecal phenol in the treatment of reflex spasms and spasticity. Lancet ii: $1102-1105$.

KERR AS 1966 Anterior rhizotomy for the relief of spasticity. Paraplegia 4:154-160.

KhALILI AA, BETTS HB 1967 Peripheral nerve block with phenol in the management of apasticity. FAMA 200:103-105.

Khalili AA, Harmel MH, Forster S, Benton JG 1964 Management of spasticity by selective peripheral nerve block with dilute phenol solutions in clinical rehabilitation. Archives of Physical Medicine and Rehabilitation 45:513-519.

Lacombe M, Audic B, Maury M 1966 Motor point injections with diluted alcohol and intrathecal injections through the vertebral foramina with absolute alcohol. Paraplegia 4:164-165.

LAITINEN L, NilsSON D, FUgL-MEYER AR 1983 Selective posterior rhizotomy for treatment of spasticity. Fournal of Neurosurgery 58:895-899.

LEHMANN W 1936 Chirurgische therapie bei erkrankungen und verletzungen des nervensystems. Ub Bumke O, Foerester O (eds): Handbuch der Neurologie vol. 8, Springer, Berlin, pp 90-265.

LIVERSEDGE LA, MAHER RM 1960 Use of phenol in relief of spasticity. British Medicalfournal ii:3133.

MAHER RM 1955 Relief of pain in incurable cancer. Lancet i:18-20.

Maiman DJ, Myklebust JB, Barolat-Romana G 1987 Spinal cord stimulation for amelioration of spasticity: Experimental results. Neurosurgery 21:331-333.

McLAUGHLIN TP, BANTA JV, GAHM NH, RAYCROFT JF 1986 Intraspinal rhizotomy and distal cordectomy in patients with myelomeningocele. Fournal of Bone and Foint Surgery 68-A.

Michaelis LS 1964 Orthopaedic Surgery of the Limbs in Paraplegia. Monograph. Springer-Verlag.

Muller H, Zierski J, Dralle D, Borner U, Hoffmann O 1987 The effects of intrathecal Baclofen on electrical muscle activity in spasticity. Fournal of Neurology 234:348-352. 
MUNRo D 1945 The rehabilitation of patients totally paralyzed below the waist: with special reference to making them ambulatory and capable of earning their living. I. Anterior rhizotomy for spastic paraplegia. New England Fournal of Medicine 233:453-461.

MUNRO D 1948 Rehabilitation of veterans paralyzed as the result of injury to the spinal cord and cauda-equina. American fournal of Surgery 75:3-18.

Nathan PW 1965 Chemical rhizotomy for relief of spasticity in ambulant patients. British Medical Fournal 1:1096-1100.

NATHAN PW 1959 Intrathecal phenol to relieve spasticity in paraplegia. Lancet ii:1099-1102.

PADOVANi R et al. 1982 The treatment of spasticity by means of dorsal longitudinal myelotomy and lozenge-shaped griseotomy. Spine 7:103-109.

Pedersen E Spasticity-Mechanism-Measurement-Management; Charles C. Thomas American Lecture Series.

PENN RD, KROIN JS 1985 Preliminary communications_continuous intrathecal Baclofen for severe spasticity. Lancet ii:125-127.

POURPRE MH 1960 Traitement neuro-chirurgical des contractures chez les paraplegiques posttraumatiques. Neurochirurgie 6:229-236.

RichaRdSON RR, MCLONE DG Percutaneous epidural neurostimulation for paraplegic spasticity. Northwestern Memorial Hospital, Northwestern University, Division of Neurosurgery, Chicago.

Romana GB, Myklebust JB, Hemmy DC, Myklebust B, Wenninger W 1985 Immediate effects of spinal cord stimulation in spinal spasticity. Fournal of Neurosurgery 65:558-562.

SCHURMANN K 1953 Uber das spatergebnis der chirurgischen behandlung extrapyramidaler bewegungsstorngen und paraplegischer zustande. Nervenarzt 24:252-253.

Scott BA, Weinstein Z, Chiteman R, Pulliam MW 1985 Intrathecal phenol and glycerin in Metrizamide for treatment of intractable spasms in paraplegia. Fournal of Neurosurgery 63:125127.

Shears AH, Nance DM 1985 Clonidine in spinal cord injury. Canadian Medical Association fournal 133:41-42.

SHELDON CH, BORS E 1948 Subarachnoid alcohol block in paraplegia. Fournal of Neurosurgery 5:385391.

Sindou M, Mifsud JJ, Rosati C, Boisson D 1987 Microsurgical selective posterior rhizotomy in the dorsal root entry zone for treatment of limb spasticity. Acta Neurochirurgica (supplement) 39:99_ 102.

WEBER W 1955 Die behandlung der spinalen paraspastik unter besonderer berucksichtigung der longitudinalen myelotomie (Bischof). Med Wschr 9:510-513.

WOOLSEY RM 1981 Symposium on spasticity and spasms. St Louis University Medical Center in cooperation with the American Paraplegia Society/The Geigy Symposia Series, 18 September. Bulletin American Paraplegia Society.

YARKONY GM, BASS LM, KEENAN V, MEYER JR PR 1985 Contractures complicating spinal cord injury: Incidence and comparison between spinal cord centre and general hospital acute care. Paraplegia 23:265-271. 